\title{
A Case of Masson's Tumor in Lateral Neck
}

\author{
Hoyoung Lee, Soo Jeong Choi, In Hak Choi, and Kwang Yoon Jung \\ Department of Otorhinolaryngology-Head and Neck Surgery, Korea University College of Medicine, Seoul, Korea
}

\section{측경부에 발생한 혈관 내 유두양 혈관내피세포 증식증 1예}

이호영 · 최수정 · 최인학 · 정광윤

고려대학교 의과대학 이비인후-두경부외과학교실

\author{
Received April 26, 2020 \\ Revised June 2,2020 \\ Accepted June 19, 2020 \\ Address for correspondence \\ Kwang Yoon Jung, MD, PhD \\ Department of Otorhinolaryngology- \\ Head and Neck Surgery, \\ Korea University \\ College of Medicine, \\ 73 Goryedae-ro, Seongbuk-gu, \\ Seoul 02841 , Korea \\ Tel $+82-2-920-5536$ \\ Fax $+82-2-925-5233$ \\ E-mail kyjungmd@gmail.com
}

\begin{abstract}
Masson's tumor, also known as intravascular papillary endothelial hyperplasia (IPEH), is a rare, benign vascular tumor characterized by the proliferation of endothelial cells with papillary formations. Differential diagnosis between IPEH and angiosarcoma is important because both have microscopic similarity. Herein, we report a rare case of IPEH on the right lateral neck of a 50-year-old female presenting with a neck mass, which was completely removed without complication. Korean J Otorhinolaryngol-Head Neck Surg 2020;63(11):541-4
\end{abstract}

Key Words Endothelium $\cdot$ Hyperplasia $\cdot$ Neck $\cdot$ Thrombosis.

\section{서 론}

혈관 내 유두양 혈관내피세포 증식증(intravascular papillary endothelial hyperplasia, IPEH)은 피부와 연조직에 발 생하는 혈관 종양 중 $2 \%$ 에 해당하는 드문 질환으로 50 세 이 하의 젊은 환자에서 발생하는 경우가 많고, 여성에서 경미하 게 발생 빈도의 우위를 보이며, 전신 어디에나 발생할 수 있으 나 측경부에서 발견되는 것은 매우 드문 경우이다. ${ }^{1,2)} \mathrm{IPEH}$ 는 혈관내피세포의 과도한 유두양 증식을 특징으로 하는 혈관 내 양성 반응성 병변으로 임상적으로나 병리학적으로 혈관 육종과 아주 유사하기 때문에 이를 정확하게 감별하는 것이 치료에 매우 중요하다. ${ }^{3,4}$

저자들은 우측 경부 종물을 주소로 내원하여 측경부의 $\mathrm{IPEH}$ 로 진단받은 환자를 경험하여 문헌고찰과 함께 보고하 는 바이다.

This is an Open Access article distributed under the terms of the Creative Commons Attribution Non-Commercial License (https://creativecommons.org/licenses/by-nc/4.0) which permits unrestricted non-commercial use, distribution, and reproduction in any medium, provided the original work is properly cited.

\section{증 례}

50세 여자 환자가 5 개월 전부터 촉지되는 통증 없는 우측 경부 종물을 주소로 내원하였다. 발열, 호흡곤란, 연하곤란 등의 증상은 없었다. 병력 청취상 수술받은 병력 및 최근에 외상을 입은 적은 없었고 좌측 양성 갑상선 결절 외 진단받 은 기저 질환은 없었다.

신체검진상 우측 경부 피하의 $10 \times 10 \mathrm{~mm}$ 크기의 무통성의 종물이 촉지되었고 그 외 다른 경부 종물은 없었다(Fig. 1). 경부 초음파와 조영 증강된 경부 컴퓨터단층촬영(enhanced neck CT)을 시행하였다. 경부 초음파상, 우측 경부 구역 $\mathrm{Vb}$ 에 $11 \times 5 \times 15 \mathrm{~mm}$ 크기의 타원형의 강한 에코를 보이는 종물 이 확인되었다. Neck CT상, 우측 흥쇄유돌근 위에 위치하는 타원형의 조영 증강되는 $10 \times 19 \mathrm{~mm}$ 크기의 종물이 우측 전 경정맥으로 배액 되는 말초혈관과 연결된 것을 확인하였다 (Fig. 2)

이에 조직학적 진단을 위해 전신마취하 우측 측경부 종물 절제술을 시행하였고, 우측 흥쇄유돌근 위에 위치한 $10 \times 10$ 
$\times 5 \mathrm{~mm}$ 크기의, 혈관이 관통하고 있는 종물을 완전 절제하 였으며 수술 중 출혈은 많지 않았다.

절제된 조직은 병리 소견상 확장된 혈관벽에서 생긴 결절 성 병변으로, 저배율에서 유두양으로 성장하는 패턴을 보이 는 방추세포로 이루어진 중간엽 종양으로 생각되었다. 고배율 에서 이 방추세포들은 핵의 비정형성을 보이지 않아 양성의 혈관 내피 세포로 사료되어 IPEH로 진단하였다. 괴사 세포 분열 혹은 핵의 비정형성은 보이지 않아 혈관 육종과 감별할 수 있었다(Fig. 3). 수술 다음날 특이 합병증 없이 퇴원하였고, 1 주 뒤 외래 종결하였다.

\section{고 찰}

IPEH는 1923년 프랑스 병리학자 $\mathrm{Masson}^{3)}$ 에 의해 처음으

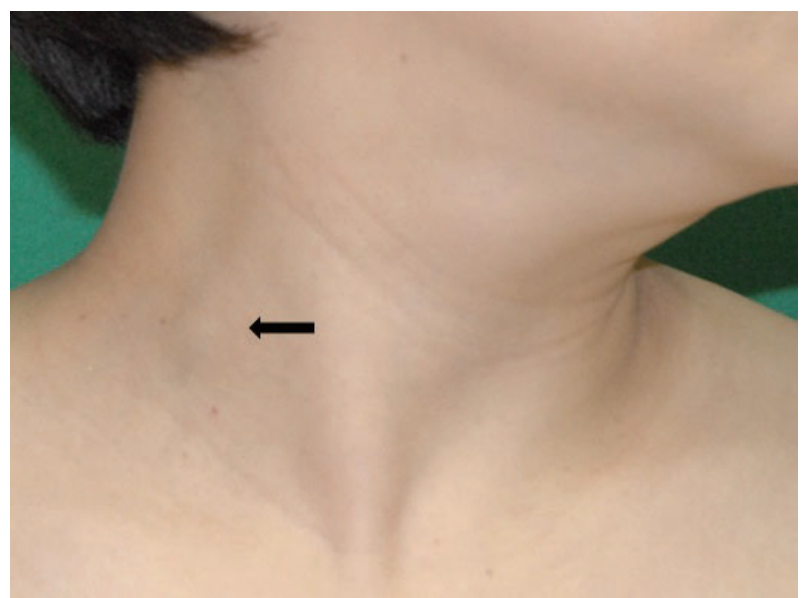

Fig. 1. $10 \times 10 \mathrm{~mm}$ nontender soft mass was palpated on right neck level $\mathrm{Vb}$ (arrow).
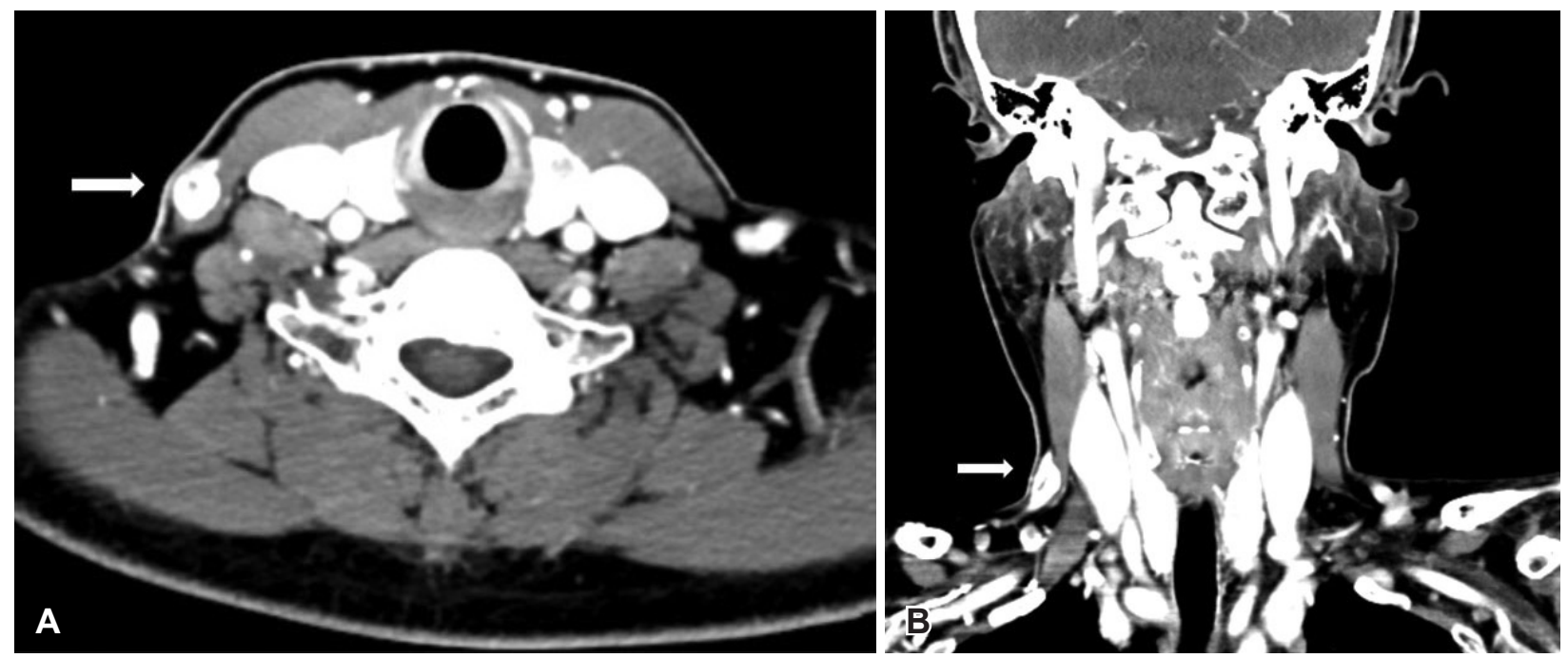

Fig. 2. Preoperative findings of enhanced CT scan. (A) is axial and (B) is coronal view showing oval shaped mass, measuring $10 \times 19$ $\mathrm{mm}$, situated over the right sternocleidomastoid muscle, with a peripheral vessel draining into the right anterior jugular vein (arrow).
로 언급된 혈관 육종과 구별되는 혈관의 양성 과형성 질환으 로 Masson's tumor, Masson's hemangioma 등으로 다양하게 일컬어져왔다. 1976년 Clearkin과 Enzinger" 가 소개한 IPEH 라는 용어가 현재 가장 널리 사용되고 있다. $\mathrm{IPEH}$ 는 전신 어 디에나 발생하는 것으로 알려져 있으며 주로 상하지, 두경부 부위에서 발생하는 것으로 알려져 있으나 측경부에서 발견 되는 경우는 매우 드물다. 문헌 고찰상 본 증례와 같이 측경 부에서 발생한 증례는 국외에서 3예가 보고되었으나 국내에 서는 보고되지 않았다(Table 1). ${ }^{6-8)}$

병인에 대해서는 명확히 밝혀져 있지 않으나 Salyer와 Saly$\mathrm{er}^{9)}$ 는 IPEH에서 혈전의 조직화 과정에서 보이는 특징적인 형 태가 관찰된다고 기술하여 혈전 생성이 원인일 수 있다는 견 해가 있다. Hashimoto 등 ${ }^{4}$ 은 $\mathrm{IPEH}$ 를 본 증례와 같이 확장된 혈관에서 발생하는 원발형(56\%), 화농성 육아종에서 발생하 는 혼합형(40\%), 그리고 혈종에서 발생하는 경우인 혈관외형 (4\%)의 3가지 형태로 구분하였다.

진단을 위해 육안적으로 검진한 후 병변의 성상과 크기를 확인하기 위해 영상학적 검사로 neck CT를 촬영할 수 있다. 이 경우 균질한 조영 증강, 불균질한 조영 증강을 나타내는 경우 ${ }^{3,10)}$ 등 병변이 다양하게 관찰될 수 있으며 본 증례에서는 병변이 경부에 국한된 균질한 조영 증강 소견을 보였다. 또한 자기공명영상도 촬영할 수 있는데 $\mathrm{T} 1$ 강조영상에서 중간신호 강도를, T2 강조영상에서 고신호강도를 보인다. ${ }^{11}$

이와 같이 영상학적 검사만으로는 $\mathrm{IPEH}$ 를 혈관종, 혈관 육종, 악성 종양과 감별하기 어려워 ${ }^{12)}$ 확진을 위해서는 조직 검사를 통해 특징적인 조직학적 소견의 확인이 필수적이다. 병리학적으로 IPEH는 혈관 내로 혈관 내피 세포의 유두양 팽창을 보이는데 이는 혈관종 및 혈관 육종에서도 나타나는 

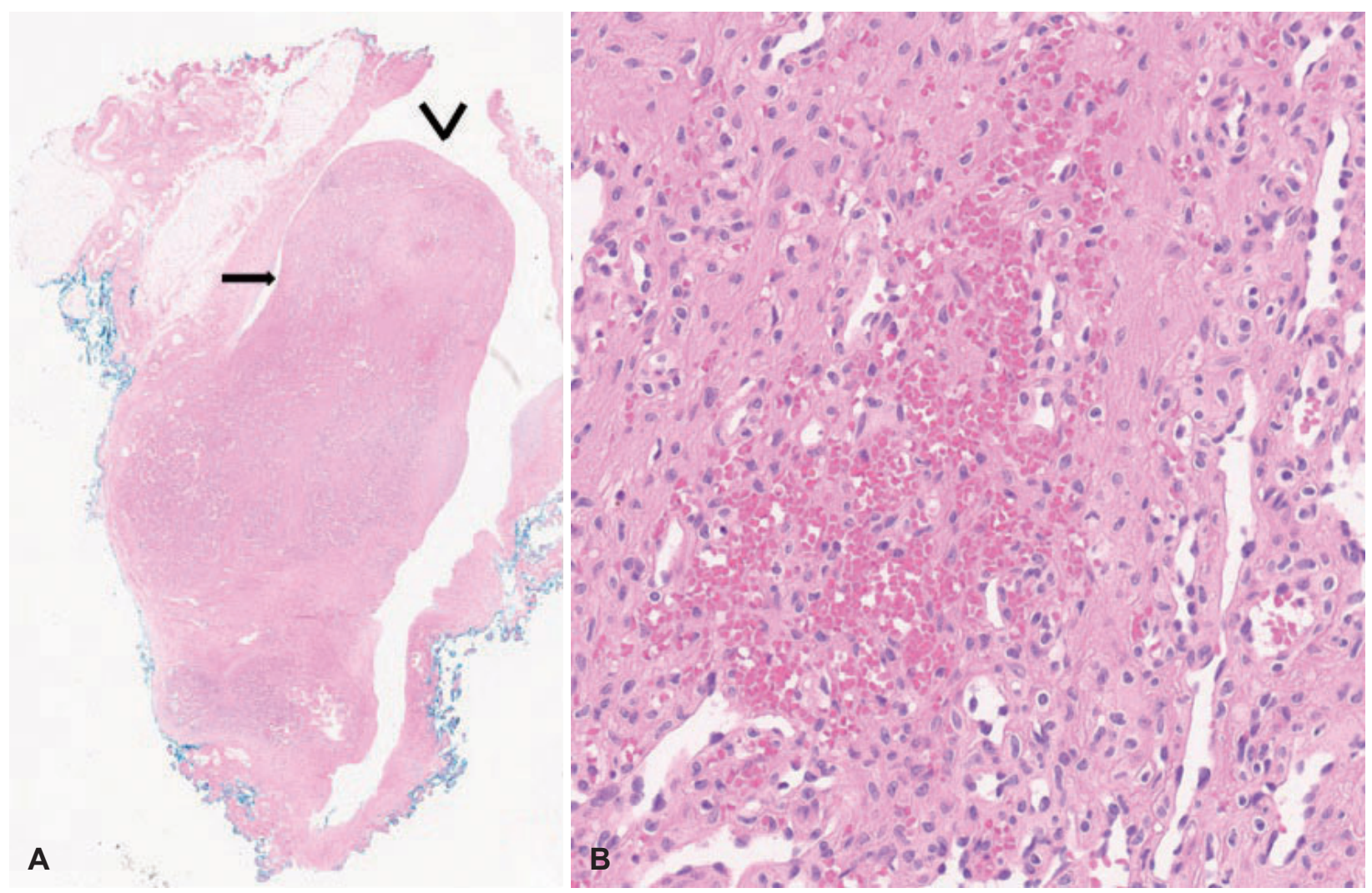

Fig. 3. Microscopic finding of intravascular papillary endothelial hyperplasia. (A) is showing proliferation of papillary structures (arrow) within intravascular space (black $v$ shape, H\&E stain $\times 10$ ). $(B)$ is showing no cellular atypia or necrosis in intravascular papillary endothelial hyperplasia (H\&E stain $\times 200)$. H\&E: hematoxylin and eosin.

Table 1. Review of previous reports of Intravascular papillary endothelial hyperplasia on lateral neck

\begin{tabular}{lclcc}
\hline \multicolumn{1}{c}{ Authors \& year } & Age/sex & Presentation & Size $(\mathrm{mm})$ & Treatment \\
\hline Pantanowitz, et al. $\left.{ }^{6}\right)$ & 2600 & Painful swelling on neck & $50 \times 40$ & Surgical excision \\
Yücesoy, et al., 2009 & 45/F & Painful swelling on neck & $90 \times 40$ & Surgical excision \\
Alotaibi, et al.. ${ }^{8)}$ 2020 & 54/M & Non-tender soft neck mass & $20 \times 10$ & Surgical excision \\
\hline
\end{tabular}

특징이므로 다른 질환들과 감별하는 것이 중요하다. IPEH에 서는 혈관 내피 세포의 팽창된 유두의 개수가 많고 조밀하게 배열되는 반면 혈관종에서는 선형으로 배열된다. ${ }^{13)}$ 혈관 육종 과 구분되는 IPEH의 특징은 주변 조직의 침범 없이 혈관 내 에 병변이 국한되며 많은 수에서 혈전이 동반되고 세포의 비 정형성 및 내부에 괴사조직이 보이지 않는다는 점이다.1,6)

본 증례의 경우 내피 세포의 증식이 혈관 내에서만 관찰되 며 종괴 내부에 비정형 소견 및 괴사 조직이 관찰되지 않아 혈관 육종을 배제하고 IPEH로 진단하였다.

$\mathrm{IPEH}$ 의 치료는 외과적 절제이며 ${ }^{6}$ 뇌나 두개골 등 위험한 부위의 수술 시에는 혈관 조영술 혹은 수술 전 색전술을 시행 할 수 있으나, 모든 부위에 대해서 시행하지는 않는다. ${ }^{14)}$ 재발 률은 낮으나 병변이 완전히 제거되지 않았을 경우 재발할 수 있고 재발한 경우에도 병변의 완전 절제를 목적으로 치료를 시행한다. 이와 달리 혈관 육종은 광범위한 수술적 절제 및
술후 방사선 치료를 요하는 경우가 많고 국소 재발 및 원격 전이가 흔히 발생하며 5년 생존률이 10 20\%라고 보고된 예 후가 불량한 질환이기 때문에, 적절한 치료를 위해 $\mathrm{IPEH}$ 와 혈관 육종을 정확히 감별하는 것이 중요하다. ${ }^{15)}$

본 증례는 측경부에 발생한 IPEH를 합병증 없이 제거한 증례로 경부의 조영 증강이 되는 종괴가 있을 때 감별해야 하는 질환들 중 드물지만 $\mathrm{IPEH}$ 를 염두에 두어야함을 상기 시키는 증례이다. 또한 IPEH는 혈관 육종과 유사한 특성을 가지나 조직학적으로 구분되는 점을 잘 기억하여 정확한 진 단을 내리고 단순 절제를 통해 치료하는 것이 중요하다.

\section{Acknowledgments}

None.

\section{Author Contribution}

Conceptualization: Hoyoung Lee, Soo Jeong Choi. Data curation: 
Hoyoung Lee, In Hak Choi. Supervision: Kwang Yoon Jung. Writing - original draft: Hoyoung Lee. Writing — review \& editing: Hoyoung Lee, Kwang Yoon Jung.

\section{ORCID}

Kwang Yoon Jung https://orcid.org/0000-0003-4316-0779

\section{REFERENCES}

1) Liné A, Sanchez J, Jayyosi L, Birembaut P, Ohl X, Poli-Mérol ML, et al. Papillary endothelial hyperplasia (Masson's tumor) in children. Ann Chir Plast Esthet 2017;62(3):232-7.

2) D’Aguanno V, Ralli M, De Virgilio A, Greco A, de Vincentiis M. The role of differential diagnosis in intravascular papillary endothelial hyperplasia of the sinonasal cavity mimicking angiosarcoma: A case report. Oncol Lett 2019;17(1):1253-6.

3) Masson P. Hemangioendotheliome vegetant intravasculaire. Bull Soc Anat (Paris) 1923;93:517.

4) Hashimoto H, Daimaru Y, Enjoji M. Intravascular papillary endothelial hyperplasia. A clinicopathologic study of 91 cases. Am J Dermatopathol 1983;5(6):539-46.

5) Clearkin KP, Enzinger FM. Intravascular papillary endothelial hyperplasia. Arch Pathol Lab Med 1976;100(8):441-4.

6) Pantanowitz L, Muc R, Spanger M, Sonnendecker H, McIntosh WA. Intravascular papillary endothelial hyperplasia (Masson's tumor) manifesting as a lateral neck mass. Ear Nose Throat J 2000;79(10):
806, 809-10, 812 passim.

7) Yücesoy C, Coban G, Yilmazer D, Oztürk E, Hekimoğlu B. Intravascular papillary endothelial hyperplasia (Masson's hemangioma) presenting as a lateral neck mass. JBR-BTR 2009;92(1):20-2.

8) Alotaibi M, Geisler V, Olze H, Knopke S. Masson tumor as a neck mass. Eur Ann Otorhinolaryngol Head Neck Dis 2020;137(3):217-8.

9) Salyer WR, Salyer DC. Intravascular angiomatosis: Development and distinction from angiosarcoma. Cancer 1975;36(3):995-1001.

10) Choi SI, Kim BH, Gong SH, Park SW. A case of intravascular papillary endothelial hyperplasia in unilateral maxillary sinus. Korean J Otorhinolaryngol-Head Neck Surg 2015;58(9):646-9.

11) Lee SH, Suh JS, Lim BI, Yang WI, Shin KH. Intravascular papillary endothelial hyperplasia of the extremities: MR imaging findings with pathologic correlation. Eur Radiol 2004;14(5):822-6.

12) McClatchey KD, Batsakis JG, Young SK. Intravascular angiomatosis. Oral Surg Oral Med Oral Pathol 1978;46(1):70-3.

13) Gurumurthy RY, Shankar NS, Mohan Raj CS, Sriram N. Sinusoidal hemangioma with secondary intravascular papillary endothelial hyperplasia. Indian J Pathol Microbiol 2020;63(2):279-81.

14) Safneck JR, Alguacil-Garcia A, Dort JC. Intranasal papillary endothelial hyperplasia. Otolaryngol Head Neck Surg 1995;113(6): 766-70.

15) Chung YM, Kang YK, Chang JS, Choi IS. Primary angiosarcoma of the parotid gland. Korean J Otorhinolaryngol-Head Neck Surg 2008;51(9):838-41. 